DOI: 10.20472/IAC.2019.045.032

\title{
OKSANA PAPELNYUK
}

National Research Moscow State University of Civil Engineering, Russian Federation

\section{EKATERINA NEZHNIKOVA}

People Friendship university of Russia, Russian Federation

\section{INVESTMENT IN DEVELOPMENT OF RENEWABLE ENERGY SOURCES AND ENERGY EFFICIENCY IN THE GLOBAL HOUSING SECTOR: MAIN FUTURES, REGULATION, TRENDS}

\begin{abstract}
:
Today, energy supply has become one of the main problems of the mankind. Needs in energy increase as technology develops. It is expected that by 2035 the world energy consumption will have increased threefold as compared to 1998. In response to these needs, fossil fuel reserves are being rapidly depleted. The widespread use of traditional energy sources in the housing, transportation and industrial sectors complicates the problem even more.Demographic, economic and cultural changes increase energy consumption in the housing sector and cause even higher levels of the related greenhouse gas emissions. The goal of this work is to identify opportunities for developing renewable energy sources (RES) in the housing sector to improve its energy efficiency.

The results of the study show that the construction industry, and especially the housing sector, can save more energy as compared to other types of the energy use. RES are important in reducing $\mathrm{CO} 2$ emissions in the housing sector and in improving the energy efficiency of buildings. In recent years, the production and consumption of energy from renewable sources in the housing sector have increased. However, the main volume of energy consumption in buildings is provided by fossil fuels. The main barriers to the introduction of renewable energy in the DNC housing system are financial ones, as well as logistical problems of biomass transportation and storage. To reduce these barriers, the authors offer a number of measures, including the governmental support for the use of renewable energy in the systems of heat supply and cooling of buildings, as well as the creation of storage facilities for renewable energy.
\end{abstract}

\section{Keywords:}

Investment, energy sources, renewable energy sources, housing sector 